\title{
Internal thoracic vein draining into the extrapericardial part of the superior vena cava: a case report
}

\author{
Drenagem da veia torácica interna para a parte extrapericárdica da \\ veia cava superior: relato de caso
}

\author{
Venkata Ramana Vollala, ${ }^{1}$ Narendra Pamidi, ${ }^{1}$ Bhagath Kumar Potu ${ }^{2}$
}

\begin{abstract}
The internal thoracic veins are venae comitantes of each internal thoracic artery draining the territory supplied by it and usually unite opposite the third costal cartilage. This single vein enters the corresponding brachiocephalic vein. We present a variation of right internal mammary vein draining into superior vena cava in a 45-year-old male cadaver. Likely development and clinical significance of the vein are discussed.
\end{abstract}

Keywords: Internal thoracic vein, superior vena cava, brachiocephalic vein, cadaver.

\section{Introduction}

Internal thoracic veins (internal mammary veins) are venae comitantes to the inferior half of the internal thoracic artery. They have several valves. Near the third costal cartilages, the veins unite and ascend medially to the artery to end in their appropriate brachiocephalic vein. Tributaries correspond to artery branches. ${ }^{1}$ The superior vena cava is formed by the junction of the brachiocephalic veins. It returns blood to the heart from the superior half of the body. It begins behind the lower border of the first right costal cartilage near the sternum, descends vertically behind the first and second intercostal spaces, and ends in the upper right atrium behind the third right costal cartilage. Its inferior half is within the fibrous pericardium, where it pierces level with the second costal cartilage. The superior vena cava has no valves. Superior vena cava tributaries are the azygos vein and small veins from the pericardium and other mediastinal structures. ${ }^{1}$ Reported variations of superior vena cava include absence of superior vena cava, ${ }^{2}$

\section{Resumo}

As veias torácicas internas são veias comitantes de cada artéria torácica interna drenando o território suprido por ela e geralmente se unem em frente à terceira cartilagem costal. Esta única veia entra na veia braquicefálica correspondente. Apresentamos uma variação da veia mamária interna direita drenando para a veia cava superior em um cadáver masculino de 45 anos. O provável desenvolvimento e a significância clínica da veia são discutidos.

Palavras-chave: Veia torácica interna, veia cava superior, veia braquiocefálica, cadáver.

persistent left superior vena cava ${ }^{3}$ and a case of bilateral superior vena cava. ${ }^{4}$ According to Bergman RA et al., the internal mammary vein occasionally receives the lateral thoracic veins. ${ }^{5}$ It may drain into the superior vena cava or the azygos vein. Anterior mediastinal masses are normally associated with thymic, thyroid, parathyroid and lymphatic origin. However, in a literature search we found a report of internal thoracic vein aneurysm presenting as an anterior mediastinal mass. ${ }^{6}$ Therefore, although isolated internal thoracic vein aneurysms presenting as enlarged masses are rare, internal thoracic vein aneurysms should be considered in the differential diagnosis of anterior mediastinal masses. Arteriovenous fistula of internal thoracic vessels is an extremely rare complication following cardiac and thoracic surgical procedures. $^{7}$

\section{Case report}

We observed a rare variation of right internal mammary vein draining into the extrapericardial part of the

1. Department of Anatomy, Melaka Manipal Medical College (Manipal Campus), International Centre for Health Sciences, Manipal, India.

2. Department of Anatomy, Kasturba Medical College, Manipal, India.

Manuscript received Sep 23, 2007, accepted for publication Jan 11, 2008.

J Vasc Bras. 2008;7(1):80-83.

Copyright $\odot 2008$ by Sociedade Brasileira de Angiologia e de Cirurgia Vascular 
superior vena cava about $1.5 \mathrm{~cm}$ distal to the junction of the right and left brachiocephalic veins (Figure 1). However, the left vein had normal course and termination. The study involved dissection of thoracic region of a 45-year-old male cadaver of South Indian origin at the department of anatomy, Melaka Manipal Medical College, Manipal, India. The dissection was carried out according to the instructions by Cunningham's manual of practical anatomy. ${ }^{8}$ A vertical skin incision extending from sternal notch to the xiphisternal joint and two horizontal incisions were performed, one extending from sternal notch to acromion process of scapula and the other from xiphisternal joint to the midaxillary line. The skin, superficial fascia, serratus anterior and pectoral muscles were removed from the upper ribs. Later, two vertical incisions were performed through the parietal pleura on either side of the sternum extending from the first to the sixth costal cartilage and horizontal incisions in the first and sixth intercostals spaces. The thoracic wall was reflected laterally and the parietal pleura was stripped to see the internal thoracic vessels. Twentyfive cadavers were dissected during educational classes to undergraduate medical students in 2005-2006. One of the specimens revealed anomalous right internal thoracic vein. The bodies were preserved by the injection of a formalin-based preservative ( $10 \%$ formalin) and stored at $-4{ }^{\circ} \mathrm{C}$. Before taking photographs, the dissected region was rinsed with water.

\section{Discussion}

Variations in venous pattern are due to deviations from the usual development. The primitive veins are essentially arranged into three sets: a) a pair of vitelline veins that drain the blood from the yolk sac; b) a pair of umbilical veins that convey oxygenated blood from the placenta to the fetus via umbilical cord; c) a pair of cardinal systems of veins; each system drains the blood from the body wall, and consists of anterior and posterior cardinal veins that unite to form right and left common cardinal veins (ducts of Cuvier).

Each anterior cardinal vein extends caudally draining the blood from the developing brain and its meninges, from the head and neck, and from the upper limb bud through subclavian veins. It joins the corresponding posterior cardinal vein to form the common

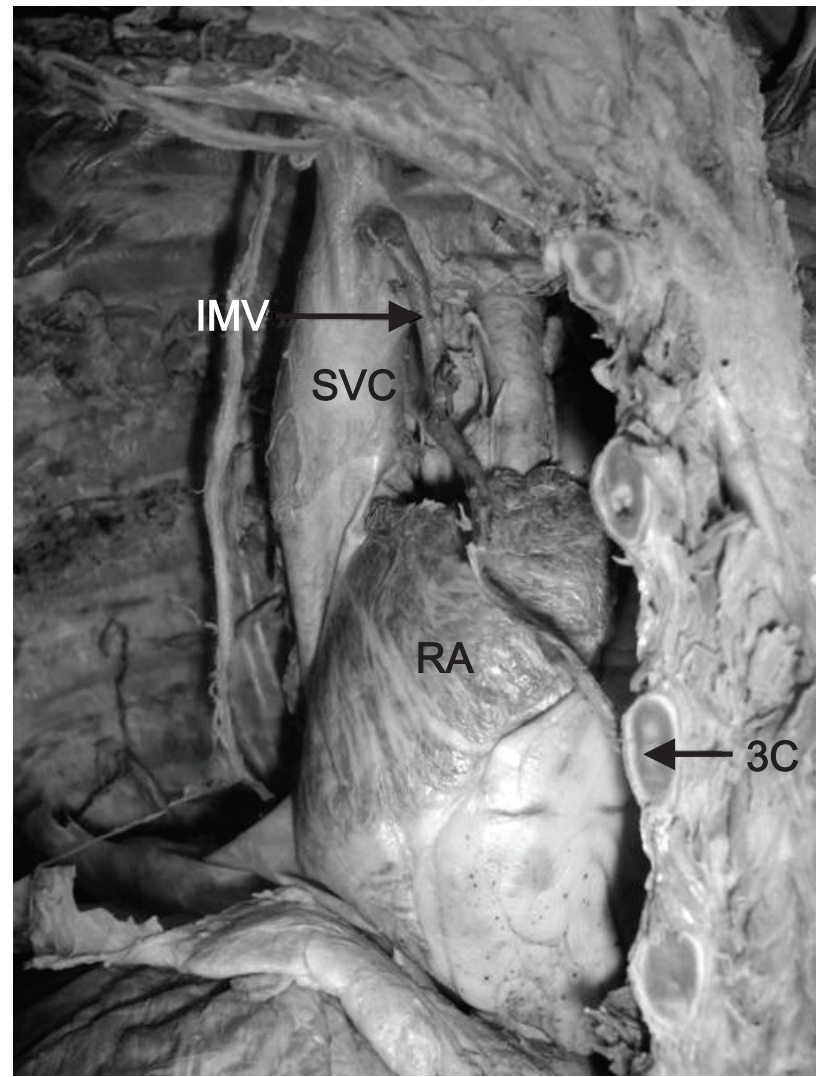

$3 \mathrm{C}=$ third costal cartilage; IMV = internal mammary vein; $\mathrm{RA}=$ right atrium; $\mathrm{SVC}=$ superior vena cava.

Figure 1 - Right internal mammary vein draining into superior vena cava

cardinal vein, which opens into the right or left horn of the sinus venosus. Soon thereafter, the anterior cardinal veins become interconnected by a transverse anastomosis, caudal to their junction with the subclavian veins (Figure 2). The oblique channel persists as the left brachiocephalic vein. The portion of each anterior cardinal vein cephalic to the subclavian vein forms the corresponding internal jugular vein. The segment of the right anterior cardinal vein between the subclavian vein and the oblique channel persists as the right brachiocephalic vein. The caudal part of the the right anterior cardinal vein and the right common cardinal vein form together the superior vena cava. ${ }^{9}$

Normally, the internal thoracic veins develop from the local venous plexus, and on the right side they drain 


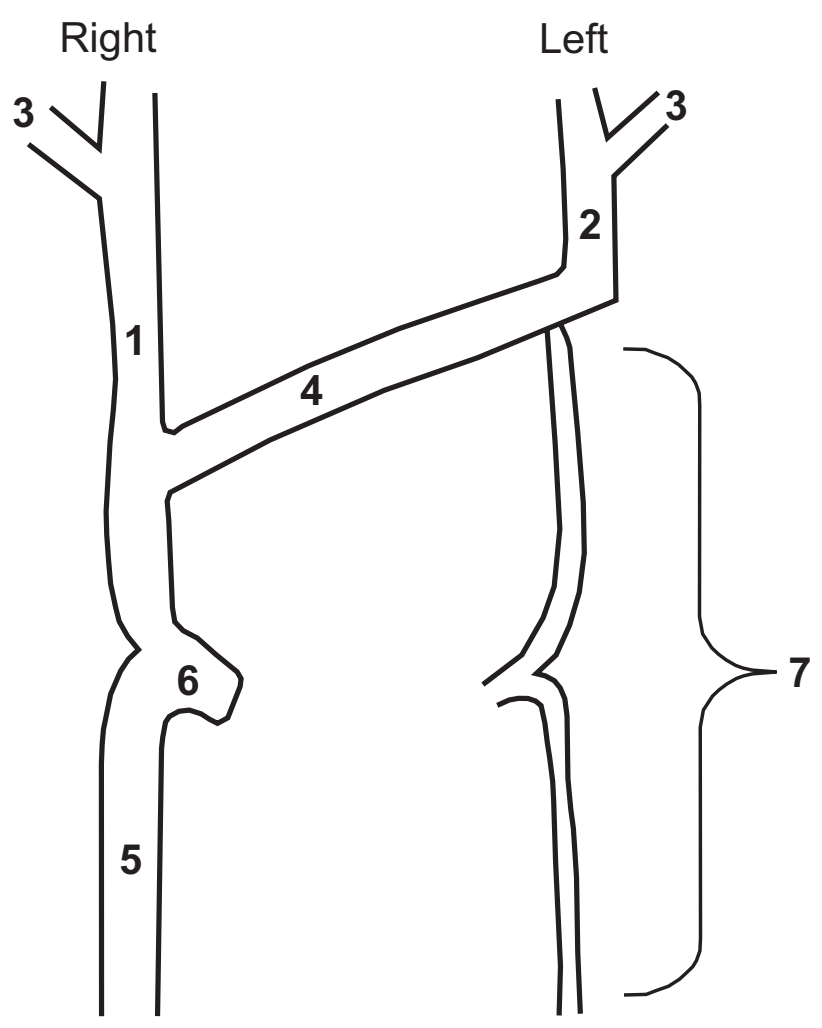

Figure 2 - Schematic diagram showing the cardinal veins: 1) right anterior cardinal vein; 2) left anterior cardinal vein; 3) subclavian vein; 4) oblique channel; 5) posterior cardinal vein; 6) right common cardinal vein; 7) degenerating left cardinal veins caudal to the transverse anastomosis

into the right anterior cardinal vein proximal to the transverse anastomosis with the left anterior cardinal vein; on the left side they drain into the left anterior cardinal vein just distal to the junction of the subclavian vein with the left anterior cardinal vein.

In the current case, the right internal thoracic vein was draining into the right anterior cardinal vein distal to the transverse anastomosis with the left anterior cardinal vein, the part which later forms the superior vena cava (Figure 3). However, on the left side, the internal thoracic vein termination was normal.

Internal thoracic blood vessels are parietal vessels of the thoracic anterior wall. Because of their position, they are often exposed to injuries during fracture of the ribs

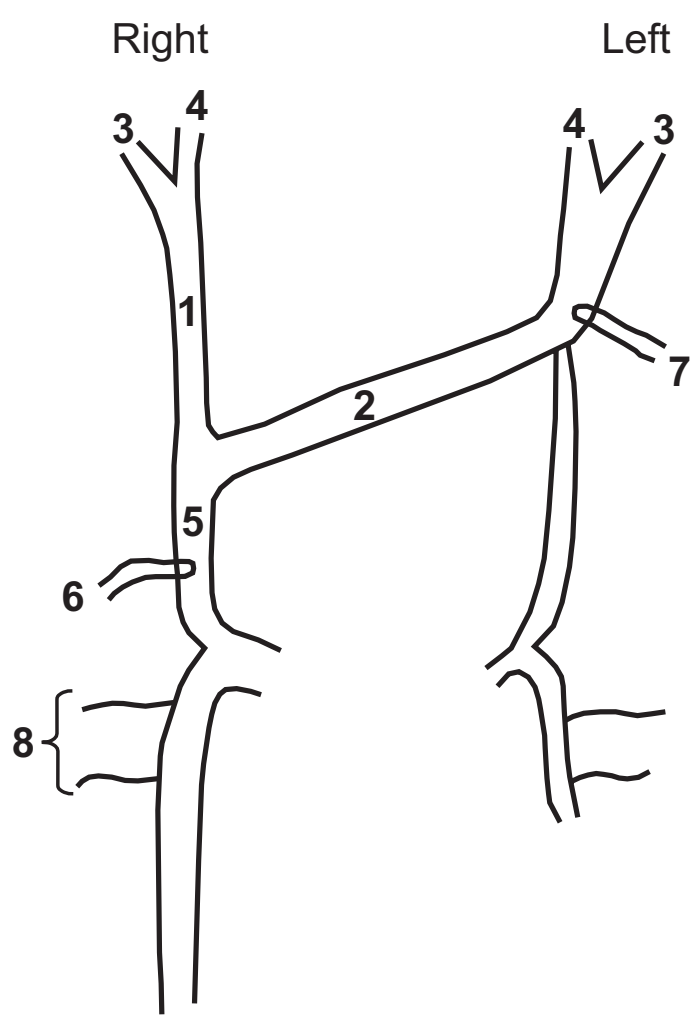

Figure 3 - Diagrammatic representation of development of major veins and right internal mammary vein opening into superior vena cava: 1) right brachiocephalic vein; 2) left brachiocephalic vein; 3) subclavian vein; 4) internal jugular vein; 5) superior vena cava; 6) right internal mammary vein; 7) left internal mammary vein; 8) intercostal veins

and sternal bone. These facts require a general knowledge about the anatomical variations of these vessels, specifically the knowledge concerning their mutual relationship, their anastomoses and their distance from the lateral margins of the sternal bone. A study by Jelicic $\mathrm{N}$ et al. revealed that the internal thoracic vein that accompanies the same-named artery could be either single or double, on one or both sides. ${ }^{10}$ In cases of double veins the artery was situated between the two of them, but in cases of single vein the vein was located medially to the artery. In $82 \%$ of cases in adults, and in $69 \%$ of cases in children, there were two veins accompanying the artery. The right and left internal thoracic veins were connected in the region of the sternal bone by the retrosternal venous net (specifically in the region of the 
manubrium) and by one venous vessel lying in front of the xiphoid process.

Knowledge of the internal mammary vessel anatomy is important to avoid hemorrhagic complications when an anterior parasternal approach is used for percutaneous transthoracic procedures, such as biopsy and empyema drainage. ${ }^{11}$ Microsurgeons currently employ the internal mammary artery and vein as recipient vessels for microvascular breast reconstruction with increasing frequency. Recent reports have demonstrated that the perforating branches of the internal mammary artery and vein can also be used as recipient vessels. ${ }^{12}$

Microvascular free tissue transfer is a standard reconstructive option for postablative defects of the head and neck. However, success of this surgery requires suitable recipient vessels in the cervical region. This form of reconstruction can be particularly challenging in the vessel-depleted neck. While the internal mammary artery and vein have been used extensively in breast reconstruction, there is a report by Urken ML et al. describing their use in head and neck reconstruction. ${ }^{13}$

Complications of central venous catheter insertion are not uncommon. Placement of a central venous catheter in the internal thoracic vein can result in pleural effusions, chest wall abscess, pulmonary edema, dyspnea and chest pain. ${ }^{14,15}$

\section{Conclusion}

This study provides general knowledge about the anatomical variations of internal thoracic veins and their clinical importance.

\section{References}

1. Standring S. Gray's anatomy. 39th ed. London: Elsevier Churchil Livingstone. 2005. p. 965, 1025.

2. Hussain SA, Chakravarty S, Chaikhouni A, Smith JR. Congenital absence of superior vena cava: unusual anomaly of superior systemic veins complicating pacemaker placement. Pacing Clin Electrophysiol. 1981;4:328-34.

3. Konishi M, Kikuchi M. [A case of persistent left superior vena cava with a horseshoe kidney]. Kaibogaku Zasshi. 1991;66:524-36.
4. Ortale JR, Grill EH. A case of bilateral superior vena cava with variations in the azygos system and in the heart. Ann Anat. 1994;176:323-5.

5. Bergman RA, Thomson SA, Afifi AK, Saadesh FA. Compendium of human anatomic variation. Munich: Urban \& Schwarzenberg; 1988.

6. Almassi GH. Internal thoracic vein aneurysm presenting as an anterior mediastinal mass. J Thorac Cardiovasc Surg. 2006;131:500-1.

7. Hassan A, Campbell DR, Bethune DC, Ali IS. Fistulae of the internal thoracic vessels: report of two cases. Eur J Cardiothorac Surg. 2002;21:358-60.

8. Romanes GJ. Cunningham's manual of practical anatomy. 15th ed. Upper and lower limbs. Oxford: Oxford University; 2003. p. 14-5.

9. Datta AK. Essentials of human embryology. 4th ed. Calcutta: Current Books International; 2000. p. 197-202.

10. Jelicic N, Djordjevic LJ, Stosic T. [The internal thoracic blood vessels (internal thoracic arteries and veins) and their practical significance]. Srp Arh Celok Lek. 1996;124:58-61.

11. Glassberg RM, Sussman SK, Glickstein MF. CT anatomy of the internal mammary vessels: importance in planning percutaneous transthoracic procedures. AJR Am J Roentgenol. 1990;155:397-400.

12. Rosson GD, Holton LH, Silverman RP, Singh NK, Nahabedian MY. Internal mammary perforators: a cadaver study. J Reconstr Microsurg. 2005;21:239-42.

13. Urken ML, Higgins KM, Lee B, Vickery C. Internal mammary artery and vein: recipient vessels for free tissue transfer to the head and neck in the vessel-depleted neck. Head Neck. 2006;28:797-801.

14. Oakes DD, Wilson RE. Malposition of a subclavian line. Resultant pleural effusions, interstitial pulmonary edema, and chest wall abscess during total parenteral nutrition. JAMA. 1975;233:532-3.

15. Brandi LS, Oleggini M, Frediani M, Lachi S, Di Trani M, Ferrannini E. Inadvertent catheterization of the internal thoracic vein mimicking pulmonary embolism: a case report. JPEN J Parenter Enteral Nutr. 1988;12:221-2.

Correspondence:

Venkata Ramana Vollala

Department of Anatomy, Melaka Manipal Medical College (Manipal Campus)

International Centre for Health Sciences

576104 - Manipal, Karnataka State - India

Tel.: +91 820-2922642

Fax: +91 820-2571905

E-mail: ramana.anat@gmail.com 